\title{
Review and update on drugs related to the development of osteonecrosis of the jaw
}

\author{
Asier Eguia ${ }^{1}$, Leticia Bagan ${ }^{2}$, Francisco Cardona ${ }^{3}$ \\ ${ }^{1}$ DDS, PhD. Associate professor. Universidad del País Vasco UPV/EHU. Leioa -Vizcaya, Spain \\ ${ }^{2} \mathrm{DDS}, \mathrm{MsC}, \mathrm{PhD}$. Associate professor. Universitat de Valencia. Valencia, Spain \\ ${ }^{3}$ MD, DDS, PhD. Head of Bucodental Health Section. Health Service of Navarra-Osasunbidea. Pamplona, Spain
}

Correspondence:

Facultad de Medicina y Enfermería. Departamento Estomatología II

Universidad del País Vasco. UPV/EHU

$B^{\circ}$ Sarriena s/n. Leioa (Vizcaya)-SPAIN. CP: 48940

asier.eguia@ehu.eus

Received: 06/05/2019

Accepted: 07/07/2019

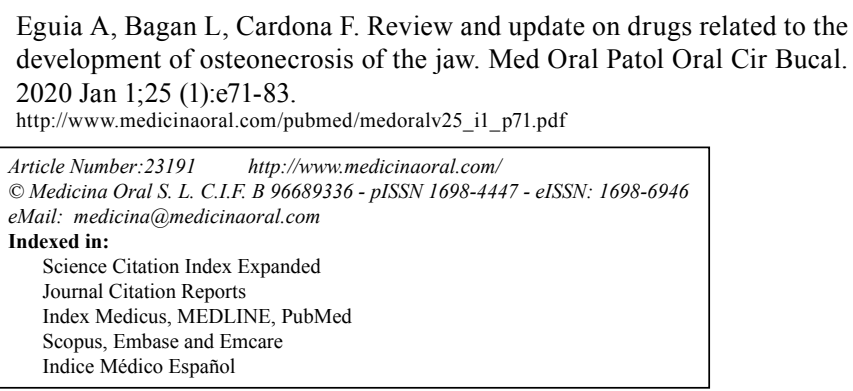

\begin{abstract}
Background: Medication-related osteonecrosis of the jaw (MRONJ) is a rare, but serious adverse effect of certain drugs, of which bisphosphonates are the most widely known. This pathology is also associated with other medications such as the biologic antiresorptive agent, denosumab and some antiangiogenics such as sunitinib, bevacizumab or aflibercept. Very recently, new medications have also been associated with osteonecrosis of the jaw (ONJ). The objectives were to update the list of medications associated with ONJ, to analyze the fundamental aspects of this list and to describe the level of evidence available.

Material and Methods: A narrative bibliographic review was made, using the PubMed-MedLine, DOAJ and SCIELO databases. Additional information was obtained through the online Medication Information Centre of the Spanish Agency of Medicines and Medical Devices (AEMPS - CIMA), the websites of the US Food \& Drugs Administration (Drugs@FDA) and the European Medicines Agency (EMA).

Results: The latest drugs identified as potential facilitators of this pathology include a number of anti-VEGF based antiangiogenic drugs and anti-TKI and different types of immunomodulators. Neither the level of evidence in this association nor the risk are equal for all these drugs. On the other hand, over the coming years, new drugs will be marketed with similar action mechanisms to those that are recognized as having this adverse effect.

Conclusions: No effective therapy is currently known for the treatment of ONJ. Therefore, in order to prevent new cases of MRONJ, it is essential for all oral healthcare professionals to be fully up-to-date with the etiopathogenic aspects of this pathology and to be aware of those drugs considered to be a risk.
\end{abstract}

Key words: Osteonecrosis of the jaw, MRONJ, bisphosphonates, antiresorptives, antiangiogenics. 


\section{Introduction}

Osteonecrosis of the jaw (ONJ) is a rare, but serious pathology and can affect both jaws, although it is more common in the mandible. It manifests itself as one or more necrotic bone lesions, generally exposed in the oral cavity and which persist for at least 8 weeks (1-4). Numerous proposals (5-17) have been put forward with regard to the staging of ONJ as can be seen in Table 1.

Table 1: Osteonecrosis of the Jaw Staging Proposal by drugs.

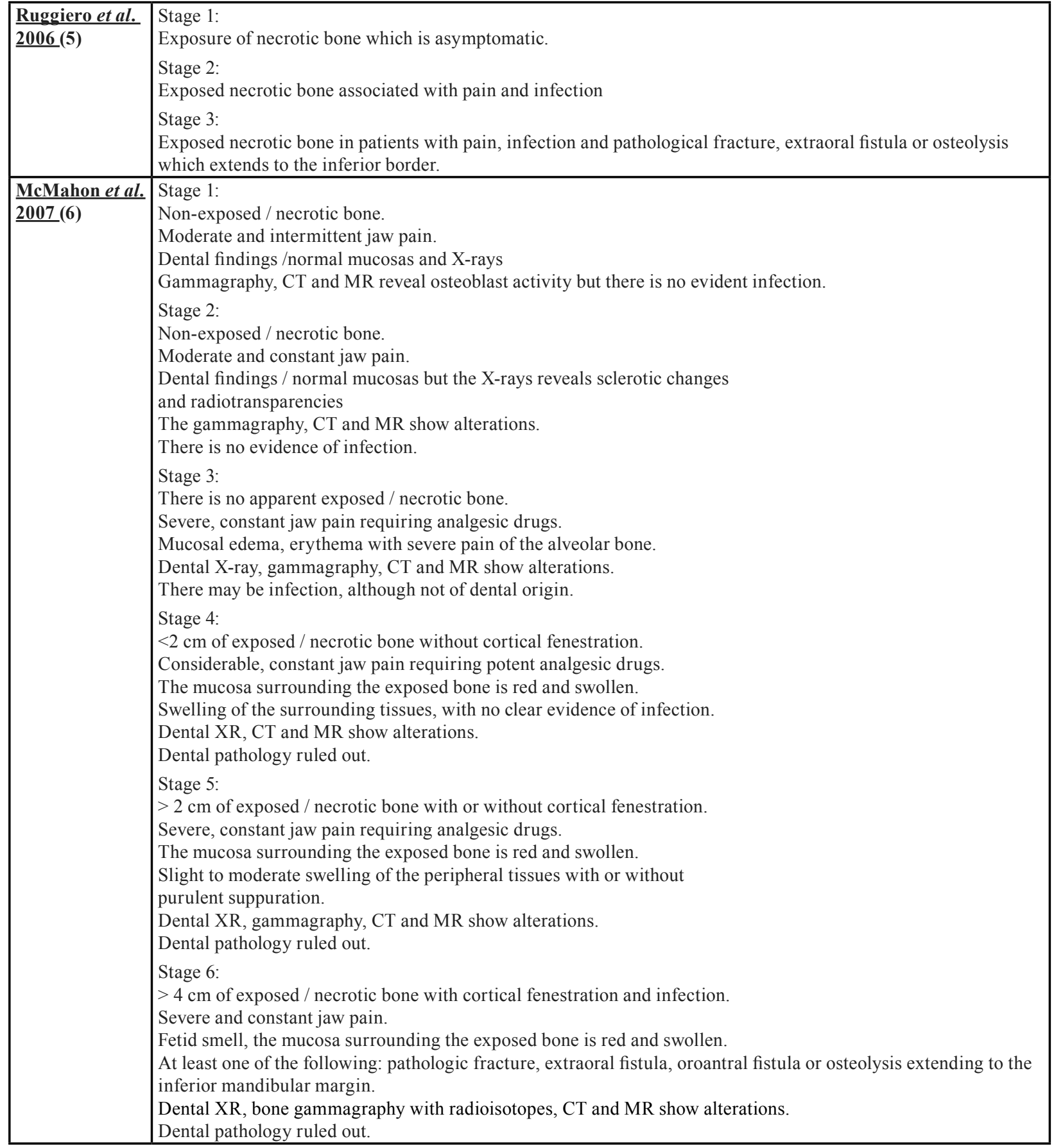


Table 1 cont.: Osteonecrosis of the Jaw Staging Proposal by drugs.

\begin{tabular}{|c|c|}
\hline $\begin{array}{l}\text { Ruggiero et al. } \\
\underline{2009}(7)\end{array}$ & $\begin{array}{l}\text { Classification of the AAOMS (American Association of Oral and Maxillofacial Surgeons) } \\
\text { Risk category: } \\
\text { There is no apparent necrotic bone in patients who have been treated with intravenous or oral bisphosphonates. } \\
\text { Stage 0: } \\
\text { There is no clinical evidence of necrotic bone, clinical findings or non-specific symptoms. } \\
\text { Stage 1: } \\
\text { Exposed necrotic bone in asymptomatic patients who present no evidence of infection. } \\
\text { Stage 2: } \\
\text { Exposed necrotic bone associated with infection, with pain and erythema in the exposed bone area with or with- } \\
\text { out purulent drainage. } \\
\text { Stage } 3 \text { : } \\
\text { Exposed necrotic bone in patients with pain, infection and one or more of the following: exposed necrotic bone } \\
\text { extending beyond the region of alveolar bone (that is, the lower border and ramus of mandible, the maxillary sinus } \\
\text { and maxillary zygoma) } \\
\text { Pathologic fracture, extraoral fistula, oral antral / oral nasal communication or osteolysis extending to the lower } \\
\text { border of the mandible of sinus floor. }\end{array}$ \\
\hline $\begin{array}{l}\text { Mawardi et al. } \\
\underline{2009}(8)\end{array}$ & $\begin{array}{l}\text { Proposal for the modification of the } 2009 \text { AAOMS classification, introducing a new stage called } 0 s . \\
\text { Stage 0s: "suspected ONJ" } \\
\text { No exposed bone. } \\
\text { Presence of fistulas, severe tooth movement, deep periodontal pockets, positive radiographic findings. } \\
2 \text { subcategories: } \\
\text { Stage 0ss: "suspect" and symptomatic. } \\
\text { Stage 0sa: "suspect" and asymptomatic. }\end{array}$ \\
\hline $\begin{array}{l}\text { Bagán et al. } \\
\underline{2009}(9)\end{array}$ & $\begin{array}{l}\text { Stage 1: } \\
\text { Presence of exposed necrotic bone or small oral fistula with no exposure of the necrotic bone. Asymptomatic. } \\
\text { Stage 2a: } \\
\text { Presence of exposed necrotic bone or small oral fistula with no exposure of the necrotic bone. } \\
\text { Patient with symptoms controlled by medical treatment. } \\
\text { Stage 2b: } \\
\text { Presence of exposed necrotic bone or small oral fistula with no exposure of the necrotic bone. } \\
\text { Patient with symptoms not controlled by medical treatment. } \\
\text { Stage 3: } \\
\text { Pathologic fracture, extraoral fistula, osteolysis extending to the inferior mandibular margin. }\end{array}$ \\
\hline $\begin{array}{l}\text { Yoneda et al. } \\
\underline{2010(10)}\end{array}$ & $\begin{array}{l}\text { The same specifications as the AAOMS in its } 2009 \text { classification, except: } \\
\text { Stage } 0 \\
\text { Includes hypoesthesia or anesthesia of the lower lip and/or deep periodontal pockets }\end{array}$ \\
\hline $\begin{array}{l}\text { Bagán et al. } \\
\underline{2012}(11)\end{array}$ & $\begin{array}{l}\text { The same stages as the classification of the AAOMS in 2009, but also: } \\
\text { Stage 3: } \\
\text { Exposed necrotic bone or oral fistula with no exposed bone, in patients with pain, infection and one or more of } \\
\text { the following: radiographic evidence of bone necrosis extending beyond the alveolar bone, pathological fracture, } \\
\text { extraoral fistula, oronasal communication, osteolysis extending to the inferior mandibular margin or sinus floor. }\end{array}$ \\
\hline $\begin{array}{l}\text { Bedogni et al. } \\
\underline{\underline{2012}(12)}\end{array}$ & $\begin{array}{l}\text { Stage } 1 \text { - Focal ONJ } \\
\text { Clinical signs and symptoms: bone exposure, tooth mobility, no post-extraction healing, fistula, inflammation, } \\
\text { abscess formation, trismus, important mandibular deformity and / or lip hypoesthesia. } \\
\text { CT findings: increased bone density limited to alveolar bone } \\
\text { (trabecular thickening and / or focal osteosclerosis), with or without the following signs: sclerotic and markedly } \\
\text { thickened lamina dura, persistent socket space and / or cortical disruption. } \\
\text { 1a. Asymptomatic } \\
\text { 1b. Symptomatic (pain and purulent secretion) } \\
\text { Stage } 2 \text { - Diffuse ONJ } \\
\text { Clinical signs and symptoms: the same as for stage 1. } \\
\text { CT findings: increased bone density extending to the basal layer (diffuse osteosclerosis), with or without the fol- } \\
\text { lowing signs: inferior dental nerve canal prominence, periosteal reaction, sinusitis, bone sequestration and / oro- } \\
\text { antral communication. } \\
\text { 2a. Asymptomatic } \\
\text { 2b. Symptomatic (pain and purulent secretion) } \\
\text { Stage } 3 \text { - Complicated ONJ } \\
\text { As for stage 2, with one or more of the following: } \\
\text { Clinical signs and symptoms: extraoral fistula. } \\
\text { Mandibular stump displacement, nasal fluid drainage. } \\
\text { CT findings: osteosclerosis of adjacent bone (zygoma, hard palate), pathological mandibular fracture and / or } \\
\text { osteolysis extending to the sinus floor. }\end{array}$ \\
\hline
\end{tabular}


Table 1 cont.: Osteonecrosis of the Jaw Staging Proposal by drugs.

\begin{tabular}{|c|c|}
\hline$\frac{\text { Patel et al. }}{\underline{2012} \text { (13) }}$ & $\begin{array}{l}\text { Modification of AAOMS } 2009 \text { classification } \\
\text { No exposed bone (NE) } \\
\text { Asymptomatic } \\
\text { Stage } 1 \mathrm{NE} \\
\text { No clinical evidence of infection; radiographic findings may be present. } \\
\text { Symptomatic } \\
\text { Stage } 2 \mathrm{NE} \\
\text { Non-exposed necrotic bone; clinical evidence of infection, presence of intraoral sinus tracts, swelling, pain, pares- } \\
\text { thesia/dysesthesia and radiographic evidence of bone necrosis. } \\
\text { Stage } 3 \text { NE } \\
\text { Non-exposed necrotic bone; pain, clinical evidence of infection and symptoms as stage } 2 \mathrm{NE} \text {, and one or more of: } \\
\text { - Radiographic evidence of necrotic bone extending beyond alveolar bone } \\
\text { - Pathologic fracture } \\
\text { - Extraoral fistula } \\
\text { - Oral antral/oral nasal communication } \\
\text { - Osteolysis extending to the inferior border of the mandible or sinus floor }\end{array}$ \\
\hline 2014 (14) & $\begin{array}{l}\text { Modification of classification of AAOMS of } 2009 \text { and Patel et. al. (2012) } \\
\text { Criteria for bone exposure (E-ONJ) } \\
\text { - Bone exposure } \\
\text { Asymptomatic } \\
\text { Name: E-ONJ, Stage } 1 \\
\text { - Bone exposure } \\
\text { Clinical symptoms of infection } \\
\text { Name: E-ONJ, Stage } 2 \\
\text { The same criteria as stage } 3 \text { of AAOMS } \\
\text { Name: E-ONJ, Stage } 3 \\
\text { Criteria for no bone exposure (E-ONJ) } \\
\text { - No bone exposure } \\
\text { Asymptomatic } \\
\text { Name: NE-ONJ, Stage } 1 \\
\text { - No bone exposure } \\
\text { Clinical symptoms of infection } \\
\text { Name: NE-ONJ, Stage } 2 \\
\text { No bone exposure, with necrosis in patients with pain, infection, and one or more of the following: } \\
\text { - Necrotic bone without exposure, as evidenced by imaging techniques, extending beyond the alveolar bone, that } \\
\text { is, inferior border and ramus of the mandible, maxillary, sinus, and zygoma in the superior maxillary. } \\
\text { - Pathologic fracture } \\
\text { - Extraoral fistula } \\
\text { - Oral antral/oral nasal communication } \\
\text { - Osteolysis extending to the inferior border of the mandible or sinus floor } \\
\text { Name: NE-ONJ, Stage } 3\end{array}$ \\
\hline $\begin{array}{l}\text { Fran } \\
\underline{2014}\end{array}$ & $\begin{array}{l}\text { Clinical and radiological findings. } \\
\text { Stage } 0 \text { : } \\
\text { No exposed bone, with non-specific radiographic findings, such as osteosclerosis and non-specific symptoms such } \\
\text { as pain. } \\
\text { Stage I: } \\
\text { Exposed bones and / or radiographic evidence of necrotic bone or persistent socket space }>2 \mathrm{~cm} \text { with or without } \\
\text { pain. } \\
\text { Stage II: } \\
\text { Exposed bones and / or radiographic evidence of necrotic bone, between } 2-4 \mathrm{~cm} \text { in diameter, with pain that re- } \\
\text { sponds to NSAIDs and possible abscesses. } \\
\text { Stage III: } \\
\text { Exposed bones and / or radiographic evidence of necrotic bone, }>4 \mathrm{~cm} \text { in greater diameter, with intense pain that } \\
\text { responds or does not respond to NSAIDs, abscesses, maxillary sinus fistulization, or mandibular nerve involve- } \\
\text { ment. }\end{array}$ \\
\hline
\end{tabular}


Table 1 cont.: Osteonecrosis of the Jaw Staging Proposal by drugs.

\begin{tabular}{|c|c|}
\hline $\begin{array}{l}\text { Mawardi } \text { et al. } \\
\underline{2015}(16)\end{array}$ & $\begin{array}{l}\text { Stage 1: } \\
\text { Asymptomatic, with bone exposure (stage 1E) or with no bone exposure (stage 1NE). } \\
\text { Stage 2: } \\
\text { Pain and infection with bone exposure (stage 2E) or with no bone exposure (stage 2NE). } \\
\text { Stage 3: } \\
\text { Greater impact, with pain and infection with bone exposure (stage 2E) or with no bone exposure (stage 2NE). }\end{array}$ \\
\hline $\begin{array}{l}\text { Yoneda } \text { et al. } \\
\underline{2017(17)}\end{array}$ & $\begin{array}{l}\text { Proposal by the Japanese Committee on Osteonecrosis of the jaw } \\
\text { Stage } 0 \text { * } \\
\text { Clinical symptoms: no bone exposure or bone necrosis, deep periodontal pocket, loose tooth, oral mucosal ulcer, } \\
\text { swelling, abscess formation, trismus, hypoesthesia / numbness of the lower lip (Vincent's symptom), non-odonto- } \\
\text { genic pain. } \\
\text { Image findings: sclerotic alveolar bone, thickening and sclerosis of the lamina dura, remaining tooth extraction } \\
\text { socket. } \\
\text { *(Care should be taken to avoid over-diagnosis given that half the stage } 0 \text { ARONJ cases do not progress to ONJ) } \\
\text { Stage } 1 \\
\text { Clinical symptoms: asymptomatic bone exposure / necrosis with no sign of infection, or fistula in which the bone } \\
\text { is palpable with a probe. } \\
\text { Image findings: sclerotic alveolar bone, thickening and sclerosis of the lamina dura, remaining tooth extraction } \\
\text { socket. } \\
\text { Stage } 2 \\
\text { Clinical symptoms: bone exposure / necrosis associated with pain, infection, fistula in which the bone is palpable } \\
\text { with a probe, or at least one of the following symptoms, including bone exposure / necrosis over the alveolar bone } \\
\text { (for example, reaching the mandibular inferior border or mandibular ramus, or reaching the maxillary sinus or } \\
\text { mandibular ramus), resulting in a pathologic fracture, extraoral fistula, nasal / maxillary sinus fistula formation, } \\
\text { or advanced osteolysis extending to the mandibular inferior border or maxillary sinus. } \\
\text { Stage } 3 \\
\text { Clinical symptoms: bone exposure / necrosis associated with pain, infection or at least one of the following } \\
\text { symptoms, or a fistula in which bone is palpable with a probe. Bone exposure / necrosis over the alveolar bone } \\
\text { (for example, reaching the mandibular inferior border or mandibular ramus, or reaching the maxillary sinus or } \\
\text { mandibular ramus or the cheekbone). As a result, pathologic fracture, or extraoral fistula, nasal / maxillary sinus } \\
\text { fistula formation, or advanced osteolysis extending to the mandibular inferior border or maxillary sinus } \\
\text { Image findings: osteosclerosis / osteolysis of the surrounding bone, pathologic mandibular fracture and osteolysis } \\
\text { extending to the maxillary sinus floor. }\end{array}$ \\
\hline
\end{tabular}

MR: Magnetic resonance, CT: Computed tomography, XR: X-ray, ONJ: Osteonecrosis of the Jaw, NSAIDs: non-steroidal anti-inflammatory drugs; ARONJ: Antiresorptive Agent-related Osteonecrosis of the Jaw.

It may be accompanied by pain, inflammation, loose teeth, erythema and suppuration. Although ONJ may occur spontaneously, in most cases it is a result of bone surgery: a tooth extraction or implant surgery, in patients who, prior to or immediately afterwards, have received pharmacological treatment with bisphosphonates, antiresorptive biologic agents or other medications detailed herein $(1-4,18)$. Fig. 1.

ONJ has a long history, dating back to the end of the 19th century, when it was first described using the term "phossy jaw" for workers (primarily women) in match making factories. These factories used white or yellow phosphorous in the manufacture of matches, prior to the Berne convention in 1906, which limited its use. This raw material was highly toxic and contained pyrophosphate that was inhaled by the workers, leading to the appearance of ONJ as well as other serious diseases $(19,20)$. In 2003, R.E. Marx (1) published an article in which, for the first time, the appearance of 36 cases of ONJ was associated with the use of intravenous bisphosphonates (zoledronate and pamidronate) in patients with multiple myeloma or metastatic breast cancer. From then onwards, numerous cases of ONJ associated with the use of systemically and orally administered bisphosphonates have been published $(1-4,18)$. Today, this relationship between bisphosphonates and ONJ is well-known, and a number of entities and associations have drafted guidelines and protocols for the prevention and treatment of this pathology (21-23).

Initially, the term BRONJ (Bisphosphonate Related OsteoNecrosis of the Jaws) was established to name this potential adverse effect (24). However, with the discovery that other medications such as the anti-RANK biologic antiresorptive agent (denosumab) (25) or the anti-VEGF antiangiogenic agent (bevacizumab) (26) and the TKI inhibitor (sunitinib) (27) could also be related to ONJ, from 2014 onwards, the term BRONJ was progressively replaced with MRONJ (Medication Related OsteoNecrosis of the Jaws) on the recommendation of the American Association of Oral and Maxillofacial Surgeons (AAOMS) (21). 


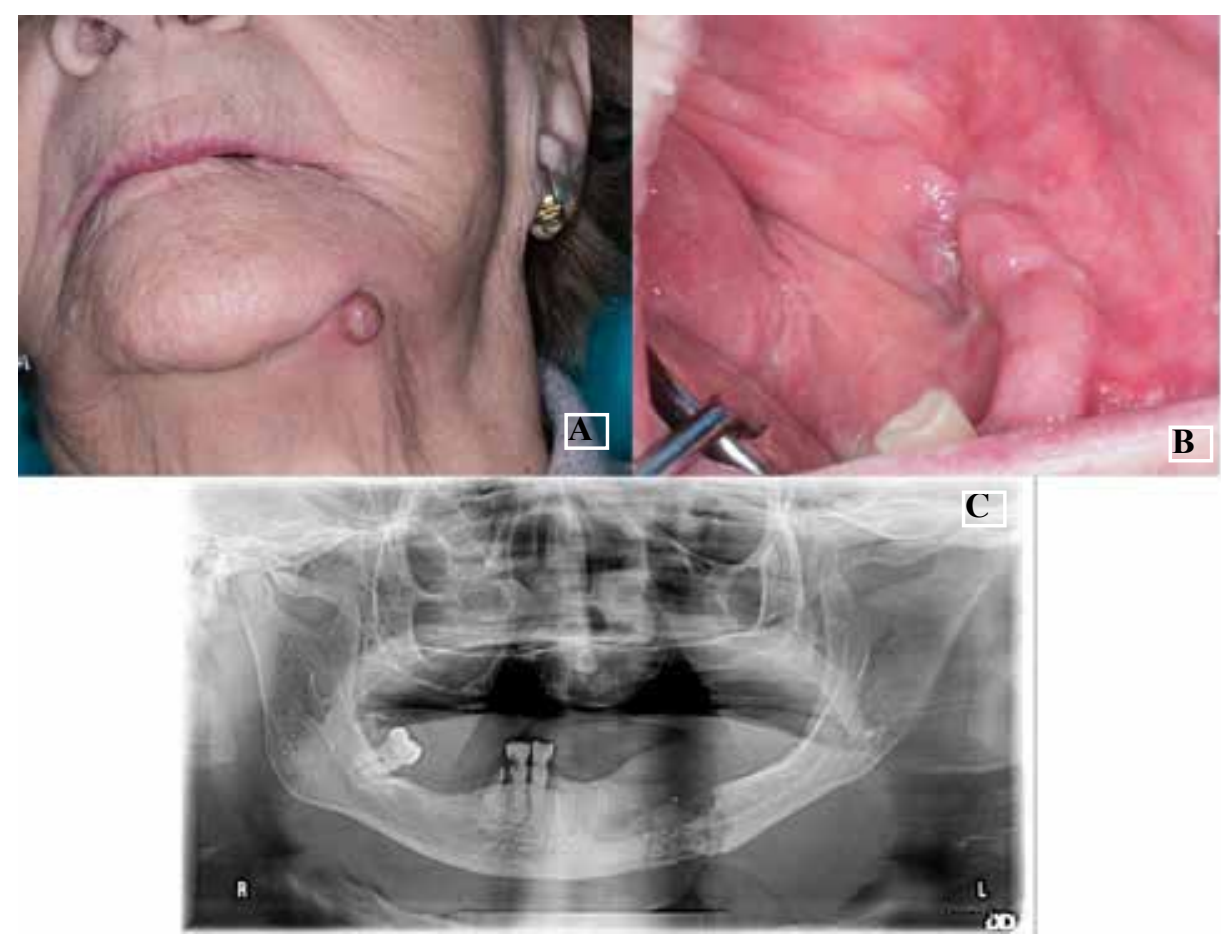

Fig. 1: 92-year-old woman. Treated with risedronate for five years due to spinal compression. History of tooth removal on the left side of mandible 4 months earlier. Exposed bone at the lingual side of lower left premolars, suppuration at this level (B) and a cutaneous fistula (A). C: The OPG shows extensive affected bone and mandibular fracture (not displaced).

At present, there is a growing list of drugs that could potentially cause ONJ, with varying levels of evidence. Although the risk of this serious adverse effect occurring varies considerably from one medication to another, it is also dependent on factors such as administration guidelines and dosage, length of treatment and the existence of concomitant systemic pathologies $(4,18,21,22)$. In view of the imminent marketing of a number of biosimilar drugs and new biologic drugs, it is logical to foresee the continued growth of the list of ONJ-related drugs over the coming years.

Currently, there is no effective treatment for MRONJ (28) and therefore prevention is essential. This paper aims to review fundamental aspects of this pathology, to update the list of drugs that are potentially related to this adverse effect, and also to review the available evidence and the level of risk of the latest medications identified in the literature. The purpose is to ensure that all healthcare professionals are aware of the possibility of the occurrence of this pathology and to remind them which medications require the application of the MRONJ prevention guidelines and protocols.

\section{Material and Methods}

A bibliographic review was made, using the PubMedMedLine, DOAJ and SCIELO databases and different combinations of the terms included in the Medical Subject Headings (MeSH) of the Index Medicus/Medline: "osteonecrosis", "jaw", "Bisphosphonate-Associated
Osteonecrosis of the Jaw", "antiresorptive drugs", "angiogenesis inhibitors" and "immunosuppressive agents". Additionally, to complete the search, the following terms were employed: "antiangiogenic", "drugrelated", "drug-induced", "MRONJ", "ARONJ", “ONJ”, "BRONJ" and "antiresorptive". Additional information sources were also used: the CIMA application (online Medication Information Centre) of the Spanish Agency of Medicines and Medical Devices (AEMPS), the websites of the US Food \& Drugs Administration (Drugs@ FDA) and the European Medicines Agency (EMA).

\section{Results}

The medications related to MRONJ cases in the scientific literature were classified by pharmacological groups, as indicated below:

- Bisphosphonates

Bisphosphonates are used in the treatment of some skeletal dysplasias such as osteogenesis imperfecta or Paget's disease, osteoporosis and the prevention of hypercalcemia and bone events associated with bone metastases $(1-4,18)$. Intravenously, they are primarily used in patients suffering from solid tumor bone metastases such as breast, prostate, bladder, lung and kidney and some lymphoproliferative processes (1-4,18). By contrast, bisphosphonates are primarily orally administered to patients suffering from osteoporosis. These drugs are able to bind to the bone matrix and, once released during bone resorption, they are able to induce 
the apoptosis of the osteoclasts (29). Due to this binding capacity, their effects can last for up to 10 years after treatment discontinuation (21). Although its mechanism of action is known, its relationship with the ONJ etiopathogenesis is only partially known $(4,18)$.

The risk of ONJ in patients taking bisphosphonates depends on a number of factors, being significantly greater in: patients receiving intravenous administration, those accumulating a higher dose and for a longer period of time, those being administered corticoids concomitantly or suffering from other systemic pathologies such as diabetes or inflammatory joint pathology $(4,18,21)$. Tobacco is probably also a negative influence, given its capacity to produce changes in the oral epithelium, to delay wound healing and to worsen the periodontal pathology (30). The relative potency of bisphosphonate is another factor that has been related to the risk of ONJ (31). "Non-nitrogenated" bisphosphonates such as etidronate and clodronate have the lowest potency and, therefore, offer a lower risk. They are principally used in rare bone dysplasias and dystrophies such as Paget's disease (31). Risedronate, ibandronate and alendronate are orally administered and are primarily used in patients with osteoporosis. Their relative potency is 10 to
100 times higher than the ones mentioned above and the prevalence of ONJ among patients is estimated at between $0.1 \%$ (10 cases $/ 10,000)$ and $0.21 \%$ (21 cases/10,000), with the risk significantly increasing from the fourth year of treatment onwards $(21,32)$. Pamidronate and zoledronate have a potency that is between 100 to 1000 times higher than the non-nitrogenated bisphosphonates and are administered intravenously, primarily in cancer patients. These are the ones at greatest risk and incidence data have been published with a variation between $0.7 \%$ and $6.7 \%$ of patients $(21,33,34)$. In smaller prospective studies, as far as the number of patients is concerned, prevalence figures of over $23 \%$ have been published (35).

The risk of ONJ in cancer patients not treated with antiresorptives, such as those assigned to the placebo group in controlled clinical trials, varies between $0 \%$ and $0.019 \%$. Analyzing this and other available data, it can be seen that the risk of ONJ in cancer patients treated with zoledronate is between 50 to 400 times greater than for those not receiving antiresorptives $(36,37)$.

Table 2 shows the list of bisphosphonates currently on the market, together with their brand name and route of administration.

Table 2: Bisphosphonates marketed in 2019. AEMPS - CIMA: Spanish Agency of Medicines and Medical Devices, Drugs@FDA: Archives of the US Food \& Drugs Administration, EMA: European Medicines Agency.

\begin{tabular}{|c|c|c|c|}
\hline Active ingredient & $\begin{array}{l}\text { Route } \\
\text { admin. }\end{array}$ & $\begin{array}{c}\text { Brand names } \\
\text { (CIMA-AEMPS) }\end{array}$ & $\begin{array}{l}\text { Other brand names } \\
\text { (FDA, EMA) }\end{array}$ \\
\hline $\begin{array}{c}\text { Etidronate } \\
\text { (Etidronate disodium) }\end{array}$ & $\mathrm{PO}$ & Osteum $\AA$ & $\begin{array}{l}\text { Etidronate disodium } \\
\text { Didronel }{ }^{\circledR} \\
\text { Ostopor } \AA\end{array}$ \\
\hline $\begin{array}{c}\text { Clodronate } \\
\text { (Clodronic Ac.) }\end{array}$ & $\mathrm{PO}$ & Bonefos ${ }^{\circledR}$ & $\begin{array}{c}\text { Clasteon } \AA \text {, Clodron } \AA \text {, Clody } \AA \text {, Difosfonal } \AA \text {, Lodronat } \AA \text {, } \\
\text { Loron } \AA \text {, Lytos } \AA \text {, Moticlod } \AA \text {, Neogrand } \AA \text {, Niklod } \AA \text {, Os- } \\
\text { tac } \AA \text {, Osteonorm } \AA \text {, Sindronat } \AA \text {, Traxovical } \AA\end{array}$ \\
\hline $\begin{array}{l}\text { Alendronate } \\
\text { (Alendronic Ac.) }\end{array}$ & $\mathrm{PO}$ & $\begin{array}{l}\text { Generic: Alendronic acid } \\
\text { Fosamax } \AA \text {, Fosavance } \AA \text {, } \\
\text { Binosto } \AA \text {, Adelan } \AA \text {, } \\
\text { Adrovance } \AA \text {, Alendrofarm } \AA \text {, } \\
\text { Semandrol } \AA\end{array}$ & $\begin{array}{c}\text { Alendronate sodium } \\
\text { *Other brand names in Europe }(>100) \text { : } \\
\text { List of nationally authorized medicinal products. Ac- } \\
\text { tive substance: alendronate } \\
\text { Procedure no.: PSUSA/00000078/201601 } \\
\text { https://www.ema.europa.eu }\end{array}$ \\
\hline $\begin{array}{c}\text { Risedronate } \\
\text { (Risedronic acid) }\end{array}$ & $\mathrm{PO}$ & $\begin{array}{c}\text { Generic: Risedronate } \\
\text { Acrel } \AA \text {, Actonel } \AA \text {, Arisocare } \AA\end{array}$ & $\begin{array}{c}\text { Risedronate sodium } \\
\text { Atelvia }{ }^{\circledR} \\
\text { *Other brand names in Europe }(>50) \text { : } \\
\text { List of nationally authorised medicinal products. Ac- } \\
\text { tive substance: alendronate } \\
\text { Procedure no.: PSUSA/00002648/201603 https://www. } \\
\text { ema.europa.eu }\end{array}$ \\
\hline $\begin{array}{c}\text { Tiludronate } \\
\text { (Tiuldronic Ac.) }\end{array}$ & $\mathrm{PO}$ & Skelid® (Withdrawn 2014) & Tiludronate disodium (Withdrawn) \\
\hline $\begin{array}{l}\text { Pamidronate } \\
\text { (Pamidronic Ac.) }\end{array}$ & IV & Generic: Pamidronate & $\begin{array}{c}\text { Pamidronate disodium } \\
\text { Aredia }{ }^{\circledR} \\
\text { *Other brand names in Europe }(>50) \text { : } \\
\text { List of nationally authorised medicinal products. Ac- } \\
\text { tive substance: alendronate } \\
\text { Procedure no.: PSUSA/00002269/201505 https://www. } \\
\text { ema.europa.eu }\end{array}$ \\
\hline $\begin{array}{l}\text { Ibandronate } \\
\text { Ibandronic Ac. }\end{array}$ & $\mathrm{PO}$ & $\begin{array}{c}\text { Generic: Ibandronic Ac. } \\
\text { Abrion } \AA \text {, Bondronat } \AA \text {, Bon- } \\
\text { viva } \AA\end{array}$ & $\begin{array}{c}\text { Ibandronate sodium } \\
\text { Boniva } \AA \text {, Bondenza } \AA \text {, Bondronat } \AA \text {, Bonviva } \AA \text {, Iasibon } \AA\end{array}$ \\
\hline $\begin{array}{l}\text { Zoledronate } \\
\text { Zoledronic Ac. }\end{array}$ & IV & Generic: Zoledronic Ac. & $\begin{array}{c}\text { Zoledronic Acid } \\
\text { Zometa } \AA \text {, Reclast } \AA\end{array}$ \\
\hline
\end{tabular}


- Biologic antiresorptives

Currently, denosumab (Prolia ${ }^{\circledR}, \operatorname{Xgeva}^{\circledR}$ ) is the main biologic antiresorptive associated with MRONJ $(18,19,21,35)$. Denosumab is a humanized monoclonal IgG2 antibody that selectively binds to the ligand of the Receptor Activator of Nuclear Factor $\kappa \beta$ (anti-RANKL) interfering in the system that regulates the bone metabolism, RANKL/RANK/OPG, emulating the biological effect of osteoprotegerin (OPG) (38). This selective blocking of the RANK ligand inhibits the activity and reduces the survival of the osteoclasts, resulting in a reduction in bone resorption and increased bone density (38). Unlike bisphosphonates, denosumab does not permanently bind to the bone matrix and, therefore, the residual effect on the remodeled bone could be minimal after 12-24 months after treatment cessation $(21,38,39)$. However, the number of studies on the residual effects of denosumab following discontinuation are limited and with only a small number of patients $(39,40)$.

Denosumab is suitable for the treatment of osteoporosis and the prevention of skeletal-related events (pathologic fracture, spinal cord compression, hypercalcemia) in adults with solid tumor bone metastases (28-40). In 2010 , shortly after it was clinically introduced, the first cases of osteonecrosis related to its use, started to be published (25). Initially, the first cases were described for patients that had previously been administered bisphosphonates, however, subsequently, numerous cases have been described of patients that have not been treated with bisphosphonates and patients that were not given denosumab for an oncology process (38-40). The pathogenic mechanism that could facilitate the appearance of ONJ is only partially known and presents some differences of interest compared to bisphosphonates, both with regard to its antiangiogenic side effects and its immunomodulatory effects (41). In clinical terms, the lesions show no difference to those associated with bisphosphonates, however in some cases they could have a better response to treatment (40). Fig. 2 .
Today, the risk of ONJ in cancer patients under treatment with denosumab is estimated to be comparable to the risk of patients treated with zoledronate, and is estimated to be between $0.7 \%$ and $1.9 \%$ (21,28-41). With regard to patients treated for osteoporosis, the risk could be far lower, estimating it to be around 0.04\% (42).

- Antiangiogenics: Anti-VEGF and Anti-TKIs

Antiangiogenics are substances of a different nature, capable of inhibiting the formation of new vessels. Due to this capacity, they are principally employed in oncology, given that neoangiogenesis is an essential process for the growth of tumors and the development of metastasis in some solid tumors (43). Of the numerous group of antiangiogenic drugs, the anti-VEGF (Vascular Endothelial Growth Factor Inhibitors) and the antiTKI (Tyrosine Kinase Inhibitors) appear to be related to a greater risk of causing MRONJ $(18,19,23)$. The precise etiopathogenesis of the ONJ associated with antiangiogenic drugs is not well know although, logically, the inhibition of angiogenesis negatively affects the bone regeneration capacity following bone aggression, delaying remodeling, healing and even increasing susceptibility to superinfection $(44,45)$. Furthermore, these drugs have other effects. For example, bevacizumab and other anti-VEGF can inhibit macrophage chemotaxis and osteoblast differentiation (46) and sunitinib and other anti-TKIs can inhibit osteoclast differentiation and other cells of the monocyte / macrophage system, conditioning the local response of the immune system (47).

In 2008, the first cases of ONJ were published for cancer patients under treatment with bevacizumab (26), in 2009 with sunitinib (27) and subsequently in 2016 with aflibercept (48). Initially, some of the first clinical cases had previous or simultaneously received bisphosphonates and other risk medications. However, shortly afterwards, dozens of new cases started to be published for patients solely treated with these medications $(4,18,44)$.

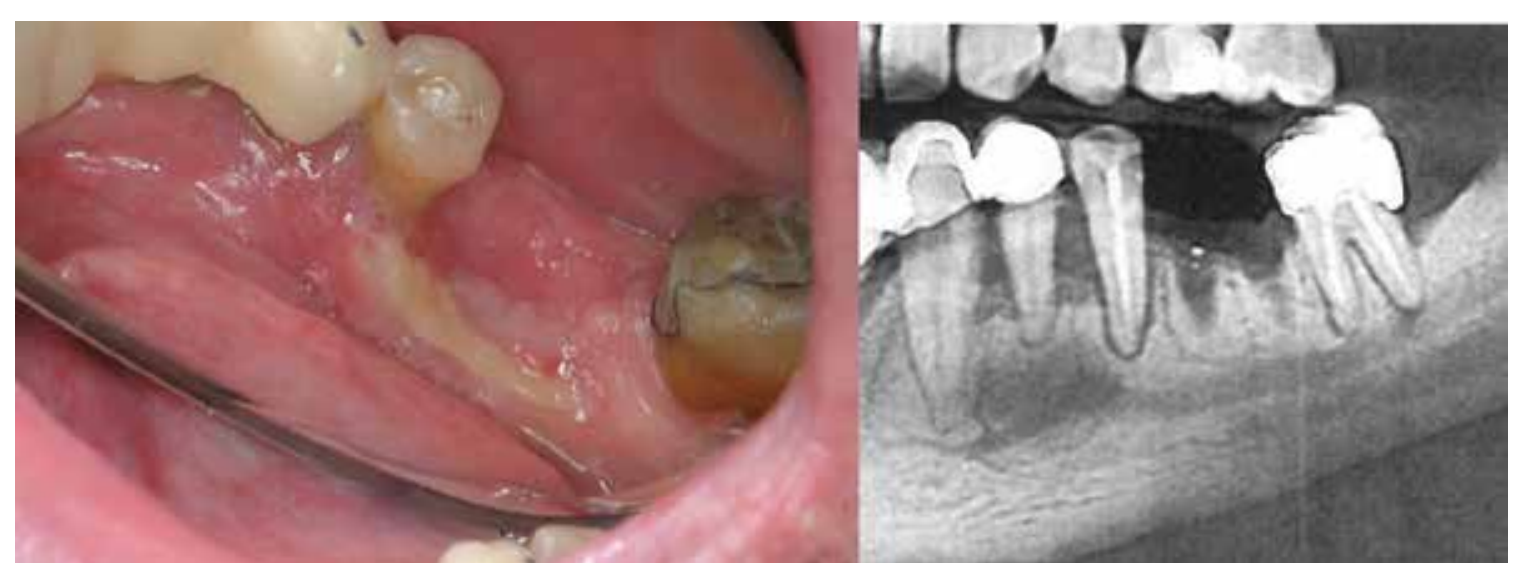

Fig 2: 50-year-old male, HIV+, in treatment for depression and osteoporosis with denosumab (Prolia) for two years. He presented to the clinic because four months ago a lower molar was extracted and it does not heal. The patient was asymptomatic. B: Detail of the OPG showing poor ossification. 
The last 5 years have also seen the publication of new cases of MRONJ associated with other antiangiogenics such as Dasatinib (49,50), Erlotinib (50), Imatinib $(50,51)$, Axitinib (52), sorafenib (53) and cabozantinib (54). Therefore, these could be considered to be risk medications for MRONJ. However, for many of these medications, it has not been possible to quantify the said risk with a certain level of evidence, neither is the etiopathogenic relationship fully known. Moreover, there is no solid evidence to determine the exact duration of the said risk following treatment discontinuation.

The ONJ cases associated with antiangiogenic drugs may appear spontaneously or following surgery and, as is the case with antiresorptives, they are also more common in the mandible. The time between the start of treatment and the appearance of ONJ is extremely variable, ranging from a few weeks to 15 months $(45,49-55)$. Table 3 gives a list of the antiangiogenic drugs that have been related to cases of MRONJ, together with their brand name and route of administration.

- Biologic immunomodulators

Biologic immunomodulators are medications, generally humanized monoclonal antibodies, specifically designed to selectively bind to one of the inflammatory response mediators $(56,57)$. Their inclusion in the battery of therapeutic products available has led to a tremendous advance in quality of life and a reduction in the severe side effects of other treatment alternatives for patients suffering from Crohn's disease, rheumatoid arthritis, ulcerative colitis, ankylosing spondylitis, or psoriatic arthritis among other diseases $(56,57)$. As well as being indicated for this use, they are also useful in the treatment of some cancer processes. Very recently, isolated cases of ONJ have been described in the scientific literature, associated with the treatment of some of these medications such as infliximab (anti-TNF $\alpha$ ) (58), adalimumab (anti-TNF $\alpha)(59,60)$ or rituximab (anti-CD20) $(61,62)$.
At present, there is no solid evidence to consider these as risk medications in relation to ONJ, given that there are no data to demonstrate a statistically significant greater incidence than in other population groups. Furthermore, there is no objective risk estimation that could potentially be used, and there is little knowledge on the etiopathogenic mechanism that could cause this adverse effect. In any case, considering the possibility of new cases appearing in the future and of being able to more definitely establish this association, it would be advisable to treat these patients with prevention protocols similar to the ones used for those taking antiresorptives or antiangiogenics.

The mechanism by which these drugs could increase the risk of ONJ has not yet been established. In the case of the anti-TNF $\alpha$, their use could produce the inhibition of the bone remodeling at the cost of an inhibition of RANKL, with apoptosis induced by activated monocytes, or they could facilitate bone colonization by certain micro-organisms as a result of local immunosuppression $(58-60,63)$. Table 4 lists the biologic immunomodulators for which cases of ONJ have been described, their brand name and the names of biosimilar products currently on the market.

- Other Immunomodulators

Corticoids: The long-term use of corticoids by the systemic route increases the risk of suffering osteonecrosis or avascular necrosis (AVN) $(64,65)$. AVN involves the death of bone tissue and its marrow due to impairment of the blood supply to the bone tissue. Its most common sites are the femur, tibia, humerus, calcaneus, or scaphoid $(64,65)$. At an oral level, corticoids do not appear to be capable of causing MRONJ by themselves, although patients concomitantly administered bisphosphonates or denosumab could have an increased risk of developing it $(21,66,67)$.

Table 3: Antiangiogenics cited in the text: brand names, action mechanism and route of administration.

\begin{tabular}{|c|c|c|c|c|}
\hline Active ingredient & $\begin{array}{c}\text { Route ad- } \\
\text { min. }\end{array}$ & Action mech. & $\begin{array}{c}\text { Brand name } \\
\text { (CIMA-AEMPS) }\end{array}$ & $\begin{array}{c}\text { Other brand names } \\
\text { (FDA, EMA) }\end{array}$ \\
\hline Bevacizumab & IV & Anti-VEGF & Avastin ${ }^{\circledR}$ & Mvasi ${ }^{\circledR}$ \\
\hline Aflibercept & IV & Anti-VEGF & Zaltrap ${ }^{\circledR}$, Eylea ${ }^{\circledR}$ & \\
\hline Pazopanib & PO & Anti-VEGF & Votrient ${ }^{\circledR}$ & Cometriq ${ }^{\circledR}$ \\
\hline Cabozantinib & PO & Anti-VEGF & Carbometyx ${ }^{\circledR}$ & Sunitinib malate \\
\hline Sunitinib & PO & Anti-TKI & Sutent ${ }^{\circledR}$ & Dasatinib \\
\hline Axitinib & PO & Anti-TKI & Inlyta ${ }^{\circledR}$ & Imatinib mesylate \\
\hline Dasatinib & PO & Anti-TKI & Sprycell ${ }^{\circledR}$ & Gleevec $\AA$ \\
\hline Imatinib & PO & Anti-TKI & Glivec ${ }^{\circledR}$ & Tarceva ${ }^{\circledR}$ \\
\hline Erlotinib & PO & Anti-TKI & Nexavar ${ }^{\circledR}$ & Sorafenib \\
\hline Sorafenib & PO & Anti-TKI & hydrochloride \\
\hline
\end{tabular}


Table 4: Immunomodulators cited in the text: brand names and route of administration.

\begin{tabular}{|c|c|c|c|c|}
\hline Active ingredient & $\begin{array}{l}\text { Route } \\
\text { admin. }\end{array}$ & Action Mech. & $\begin{array}{c}\text { Brand name } \\
\text { (CIMA-AEMPS) }\end{array}$ & $\begin{array}{c}\text { Biosimilar } \\
\text { (AEMPS, FDA, EMA) }\end{array}$ \\
\hline Infliximab & IV & Anti-TNF $\alpha$ & Remicade ${ }^{\circledR}$ & 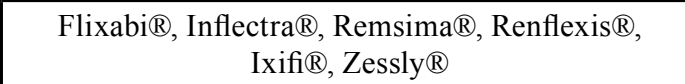 \\
\hline Adalimumab & IV & Anti-TNF $\alpha$ & Humira ${ }^{\circledR}$ & 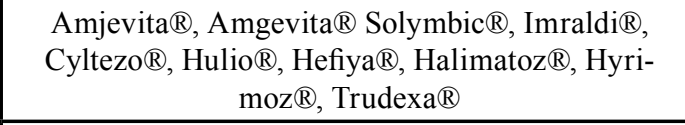 \\
\hline Rituximab & IV & Anti-CD20 & Mabthera ${ }^{\circledR}$ & 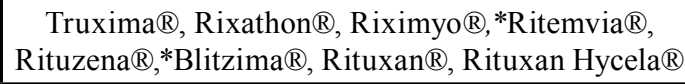 \\
\hline Active ingredient & $\begin{array}{l}\text { Route } \\
\text { admin. }\end{array}$ & \multicolumn{2}{|c|}{$\begin{array}{c}\text { Brand name } \\
\text { (CIMA-AEMPS) }\end{array}$} & $\begin{array}{l}\text { Other brand names } \\
\text { (FDA,EMA) }\end{array}$ \\
\hline Methotrexate & $\mathrm{PO} / \mathrm{IV}$ & \multicolumn{2}{|c|}{$\begin{array}{c}\text { Generic: Methotrexate } \\
\text { Imeth } \AA \text {, Metoject } \AA \text {, Nordimet } \AA \text {, } \\
\text { Bertanel } \AA \text {, Glofer } \AA \text {, Quinux } \AA\end{array}$} & $\begin{array}{c}\text { Methotrexate sodium } \\
\text { Folex } \AA \text {, Abitrexate } \AA \text {, Mexate } \AA \text {, Otrexup Rasuvo } \AA \text {, } \\
\text { Trexall } \AA \text {, Xatmep } \AA\end{array}$ \\
\hline Temsirolimus & IV & \multicolumn{2}{|c|}{ Torisel $®$} & \\
\hline Everolimus & $\mathrm{PO}$ & \multicolumn{2}{|c|}{ Certican $\AA$, Afinitor $\AA$, Votubia ${ }^{\circledR}$} & \\
\hline
\end{tabular}

Methotrexate: Methotrexate (MTX) is one of the key drugs used in the treatment of rheumatoid arthritis (RA) and other autoimmune disorders and inflammatory diseases (68). Furthermore, it is a cytotoxic medication that is indicated in the treatment of a number of solid tumors and haematological malignancies $(68,69)$. The association of MTX with ONJ has some controversial aspects. Thus, in many cases described in the literature, in addition to MTX, patients had also been treated previously or concomitantly with bisphosphonates and/or corticoids (70). On the other hand, in some cases, the presence of necrotic bone could be secondary to a Methotrexate-related chronic lymphoproliferative disorder and it would therefore be arguable whether it should be considered as MRONJ, in the absence of a detailed histopathological study of the lesion (71). However, authors such as Henien et al. (72), have recently described cases of MRONJ in patients treated for RA with low oral doses of MTX over long periods of time, in the absence of a lymphoproliferative disorder and with no administration of other antiresorptive or antiangiogenic medications. The exact etiopathogenic mechanism of its possible association with MRONJ is unknown, although it appears to be primarily associated with its immunomodulating effects. MTX inhibits DNA synthesis, cell proliferation in the $\mathrm{S}$ phase cell cycle, it is cytotoxic in high doses while in low doses in inhibits $\mathrm{T}$ and $\mathrm{B}$ lymphocyte functions and proliferation, and inhibits the release of IL-1, TNF $\alpha$ and other cytokines $(73,74)$. However, it could also be partly related to its great capacity to inhibit osteoblast proliferation $(73,74)$.

mTOR inhibitors: Everolimus and Temsirolimus are inhibitors of mTOR (mammalian target of rapamycin) with antiangiogenic and immunosuppressive properties $(75,76)$. They are primarily used to prevent transplant rejection and, at higher doses, they are used in the treatment of advanced stages of breast and kidney cancer, some neuroendocrine tumors and some types of leukemia $(75,76)$. Most of the MRONJ related to Everolimus or Temsirolimus have been described in patients simultaneously receiving bisphosphonates $(77,78)$, denosumab (79) or other antiangiogenics $(80,81)$. However, MRONJ cases have recently been described in patients solely treated with Everolimus (82). The MRONJ cases described in the literature and associated with the mTOR inhibitors, do not appear to have different clinical characteristics to those associated with other medications (77-82). Given the paucity of clinical cases described up to now, it is not possible to estimate the level of risk for these medications in relation to MRONJ.

Table 4 also provides a summary of the brand names of the non-biologic immunomodulators associated with MRONJ.

- Other medications

Isolated cases of MRONJ have been described for other drugs, although it has not yet been possible to completely clarify the etiopathogenesis for this possible relationship. These drugs include ipilimumab (Yervoy ${ }^{\circledR}$ ), an anti-CTLA-4 monoclonal antibody indicated for the treatment of advanced melanoma (83) or azacitidine (Vidaza ${ }^{\circledR}$ ), a chemotherapy drug used in the treatment of some types of myelodysplastic syndromes and leukemia (84). At present, new investigations are required in order to ascertain whether these medications are related to a risk of MRONJ. 


\section{Discussion}

15 years after the first cases were reported relating to the development of ONJ with the use of bisphosphonates, there is still no effective treatment despite the different therapeutic options available $(1,21-24)$. Prevention is key to controlling this severe pathology, which can have an important effect on a patient's quality of life (21-23). Its prevalence is extremely variable, depending on the drug, cause, duration and prescription dose, and the existence of other concomitant pathologies. The risk is low for those patients taking bisphosphonates or denosumab orally for osteoporosis and with no administration of corticoids and not suffering from other pathologies (21-23). However, this risk increases considerably from the fourth year of treatment onwards and is far higher in those patients receiving the intravenous administration of bisphosphonates. With regard to other medications, it is difficult to do a risk estimate due to the paucity of studies with a high level of evidence.

Although MRONJ may develop spontaneously, more than $60 \%-70 \%$ of cases, primarily dependent on the type of medication, occur following a dental extraction, implant surgery or any other type of jaw surgery (2123). On occasions, even excessive pressure or a decubitus ulcer caused by removable dentures may trigger one of these lesions (21-23). Therefore, in view of the foregoing, in order to prevent MRONJ, it is essential for all healthcare professionals to have a thorough knowledge of the key clinicopathologic and etiopathogenic principles of this pathology.

Reviewing the literature, it can be observed how new drugs have been progressively added over the last few years to the list of drugs related to MRONJ, with a varying level of evidence. The patent of some biologic medications related to MRONJ has recently expired and, following approval, its biosimilar products have started to be used, although obviously to a lesser extent than the original products. Biosimilar drugs are not exact copies of the original biologic medication. However, they are designed to have the same biologic effect and, therefore, their possible adverse effects could also be very similar. Moreover, looking at the clinical trial registers such as ClinicalTrials.gov or EU Clinical Trials Registers, many more biosimilar medications related to MRONJ are already close to being marketed.

In view of the serious public health problem caused by MRONJ, it appears to be extremely important to ensure that all healthcare professionals are fully up-to-date with the complete list of risk medications, prevention protocols and consent documents prepared by the different entities and organizations in this field. Unfortunately, many of the documents available for consent, positioning and action protocols for this type of patient, are not up-to-date and do not include information on the drugs that have most recently come to be suspected of causing this side effect.

\section{Conclusions}

Not only bisphosphonates are capable of inducing ONJ. A growing list of medications probably have this same side effect, with a higher or lower risk. Although a high level of evidence does not exist for these medications, it would be important, from a preventive point of view, to apply clinical protocols that are the same or similar to the ones used for patients administered bisphosphonates or denosumab. Over the next 2 to 3 years, it would be advisable to treat with particular care those patients under treatment with new biologic antiresorptives and anti-inflammatory drugs, and any other new antiangiogenic or immunosuppressant.

\section{References}

1. Marx RE. Pamidronate (Aredia) and Zoledronate (Zometa) induced avascular necrosis of the jaws: a growing epidemic. J Oral Maxillofac Surg. 2003;61:1115-7.

2. Ruggiero SL, Mehrotra B, Rosenberg TJ, Engroff SL. Osteonecrosis of the jaws associated with the use of Bisphosphonates: a review of 63 cases. J Oral Maxillofac Surg. 2004;62:527-34.

3. Bagan JV, Murillo J, Jimenez Y, Poveda R, Milian MA, Sanchis $\mathrm{JM}$, et al. Cancer chemotherapy induced avascular jaw osteonecrosis: series of 10 cases. J Oral Pathol Med. 2005;34:120-3.

4. McGowan K, McGowan T, Ivanovski S. Risk factors for medication-related osteonecrosis of the jaws: A systematic review. Oral Dis. 2018;24:527-536.

5. Ruggiero SL, Fantasia J, Carlson E. Bisphosphonate-related osteonecrosis of the jaw: background and guidelines for diagnosis, staging and management. Oral Surg Oral Med Oral Pathol Oral Radiol Endod. 2006;102:433-41.

6. McMahon RE, Bouquot JE, Glueck CJ, Griep JA, Adams WR, Spolnik KJ, et al. Staging bisphosphonate-related osteonecrosis of the jaw should include early stages of disease. J Oral Maxillofac Surg. 2007;65:1899-900.

7. Ruggiero SL, Dodson TB, Assael LA, Landesberg R, Marx RE, Mehrotra B, et al. American Association of Oral and Maxillofacial Surgeons position paper on bisphosphonate-related osteonecrosis of the jaw - 2009 update. J Oral Maxillofac Surg. 2009;67:2-12.

8. Mawardi H, Treister N, Richardson P, Anderson K, Munshi N, Faiella RA, et al. Sinus tracts - an early sign of bisphosphonate associated osteonecrosis of the jaws?. J Oral Maxillofac Surg. 2009;67:593-601. 9. Bagan JV, Jimenez Y, Diaz JM, Murillo J, Sanchis JM, Poveda R, et al. Osteonecrosis of the jaws in intravenous bisphosphonate use: proposal for a modification of the clinical classification. Oral Oncol. 2009;45:645-6.

10. Yoneda T, Hagino H, Sugimoto T, Ohta H, Takahashi S, Soen S, et al. Bisphosphonate-related osteonecrosis of the jaw: position paper from the Allied Task Force Committee of Japanese Society for Bone and Mineral Research, Japan Osteoporosis Society, Japanese Society of Periodontology, Japanese Society for Oral and Maxillofacial Radiology, and Japanese Society of Oral and Maxillofacial Surgeons. J Bone Miner Metab. 2010;28:365-83.

11. Bagan JV, Hens-Aumente E, Leopoldo-Rodado M, Poveda-Roda R, Bagan L. Bisphosphonate-related osteonecrosis of the jaws: study of the staging system in a series of clinical cases. Oral Oncol. 2012;48:753-7.

12. Bedogni A, Fusco V, Agrillo A, Campisi G. Learning from experience. Proposal of a refined definition and staging system for bisphosphonate-related osteonecrosis of the jaw (BRONJ). Oral Dis. 2012;18:621-3

13. Patel S, Choyee S, Uyanne J, Nguyen AL, Lee P, Sedghizadeh $\mathrm{PP}$, et al. Non-exposed bisphosphonate-related osteonecrosis of the jaw: a critical assessment of current definition, staging, and treatment guidelines. Oral Dis. 2012;18:625-32. 
14. Schiodt M, Reibel J, Oturai P, Kofod T. Comparison of nonexposed and exposed bisphosphonate-induced osteonecrosis of the jaws: a retrospective analysis from the Copenhagen cohort and a proposal for an updated classification system. Oral Surg Oral Med Oral Pathol Oral Radiol. 2014;117:204-13.

15. Franco S, Miccoli S, Limongelli L, Tempesta A, Favia G, Maiorano $\mathrm{E}$, et al. New dimensional staging of bisphosphonate-related osteonecrosis of the jaw allowing a guided surgical treatment protocol: long-term follow-up of 266 lesions in neoplastic and osteoporotic patients from the university of bari. Int J Dent. 2014;2014:935657.

16. Mawardi H, Woo SB. Medication-related osteonecrosis of the jaws, stage 0 --do we need stage 0 any more?. J Oral Maxillofac Surg. 2015;73:797-7.

17. Yoneda T, Hagino H, Sugimoto T, Ohta H, Takahashi S, Soen S, et al. Antiresorptive agent-related osteonecrosis of the jaw: Position Paper 2017 of the Japanese Allied Committee on Osteonecrosis of the Jaw. Japanese Allied Committee on Osteonecrosis of the Jaw. J Bone Miner Metab. 2017;35:6-19.

18. Otto S, Pautke C, Van den Wyngaert T, Niepel D, Schiødt M. Medication-related osteonecrosis of the jaw: Prevention, diagnosis and management in patients with cancer and bone metastases. Cancer Treat Rev. 2018;69:177-87.

19. Jacobsen C, Zemann W, Obwegeser JA, Grätz KW, Metzler P. The phosphorous necrosis of the jaws and what can we learn from the past: a comparison of "phossy" and "bisphossy" jaw. Oral Maxillofac Surg. 2014;18:31-7.

20. Pollock RA, Brown TW Jr, Rubin DM. "Phossy Jaw" and "Bisphossy Jaw" of the 19th and the 21st Centuries: The Diuturnity of John Walker and the Friction Match. Craniomaxillofac Trauma Reconstr. 2015;8:262-70.

21. Ruggiero SL, Dodson TB, Fantasia J, Goodday R, Aghaloo T, Mehrotra B, et al. American Association of Oral and Maxillofacial Surgeons. American Association of Oral and Maxillofacial Surgeons position paper on medication-related osteonecrosis of the jaw--2014 update. J Oral Maxillofac Surg. 2014;72:1938-56.

22. Khan AA, Morrison A, Kendler DL, Rizzoli R, Hanley DA, Felsenberg D, et al. Case-Based Review of Osteonecrosis of the Jaw (ONJ) and Application of the International Recommendations for Management From the International Task Force on ONJ. J Clin Densitom. 2017;20:8-24

23. Khan AA, Morrison A, Hanley DA, Felsenberg D, McCauley LK, O'Ryan F, et al. Diagnosis and management of osteonecrosis of the jaw: a systematic review and international consensus. J Bone Miner Res. 2015;30:3-23.

24. Yeo AC, Lye KW, Poon CY. Bisphosphonate-related osteonecrosis of the jaws. Singapore Dent J. 2005;27:36-40.

25. Taylor KH, Middlefell LS, Mizen KD. Osteonecrosis of the jaws induced by anti-RANK ligand therapy. Br J Oral Maxillofac Surg. 2010;48:221-3.

26. Van Poznak C. Osteonecrosis of the jaw and bevacizumab therapy. Breast Cancer Res Treat. 2010;122:189-91.

27. Brunello A, Saia G, Bedogni A, Scaglione D, Basso U. Worsening of osteonecrosis of the jaw during treatment with sunitinib in a patient with metastatic renal cell carcinoma. Bone. 2009;44:173-5.

28. Beth-Tasdogan NH, Mayer B, Hussein H, Zolk O. Interventions for managing medication-related osteonecrosis of the jaw. Cochrane Database Syst Rev. 2017;10:CD012432.

29. Tai TW, Su FC, Chen CY, Jou IM, Lin CF. Activation of p38 MAPK-regulated Bcl-xL signaling increases survival against zoledronic acid-induced apoptosis in osteoclast precursors. Bone. 2014;67:166-74

30. Quispe D, Shi R, Burton G. Osteonecrosis of the jaw in patients with metastatic breast cancer: ethnic and socio-economic aspects. Breast J. 2011;17:510-3.

31. Hamadeh IS, Ngwa BA, Gong Y. Drug induced osteonecrosis of the jaw. Cancer Treat Rev. 2015;41:455-64.

32. Lo JC, O'Ryan FS, Gordon NP, Yang J, Hui RL, Martin D, et al. Prevalence of osteonecrosis of the jaw in patients with oral bisphosphonate exposure. J Oral Maxillofac Surg. 2010;68:243-53.
33. Krstevska S, Stavric SG, Cevrevska L, Georgjievski B, Karanfilski O, Sotirova T, et al. Osteonecrosis of the Jaw After Bisphosphonates Treatment in Patients with Multiple Myeloma. Med Arch. 2015;69:367-70.

34. Vahtsevanos K, Kyrgidis A, Verrou E, Katodritou E, Triaridis $\mathrm{S}$, Andreadis CG, et al. Longitudinal cohort study of risk factors in cancer patients of bisphosphonate-related osteonecrosis of the jaw. J Clin Oncol. 2009;27:5356-62.

35. Boonyapakorn T, Schirmer I, Reichart PA, Sturm I, Massenkeil G. Bisphosphonate-induced osteonecrosis of the jaws: prospective study of 80 patients with multiple myeloma and other malignancies. Oral Oncol. 2008;44:857-69.

36. Qi WX, Tang LN, He AN, Yao Y, Shen Z. Risk of osteonecrosis of the jaw in cancer patients receiving denosumab: a meta-analysis of seven randomized controlled trials. Int J Clin Oncol. 2014;19:403-10. 37. Mauri D, Valachis A, Polyzos IP, Polyzos NP, Kamposioras K, Pesce LL. Osteonecrosis of the jaw and use of bisphosphonates in adjuvant breast cancer treatment: a meta-analysis. Breast Cancer Res Treat. 2009;116:433-9.

38. Deeks ED. Denosumab: A Review in Postmenopausal Osteoporosis. Drugs Aging. 2018;35:163-73.

39. Iranikhah M, Deas C, Murphy P, Freeman MK. Effects of Denosumab After Treatment Discontinuation: A Review of the Literature. Consult Pharm. 2018;33:142-51.

40. Aljohani S, Gaudin R, Weiser J, Tröltzsch M, Ehrenfeld M, Kaeppler G, et al. Osteonecrosis of the jaw in patients treated with denosumab: A multicenter case series. J Craniomaxillofac Surg. 2018;46:1515-25.

41. Baron R, Ferrari S, Russell RG. Denosumab and bisphosphonates: different mechanisms of action and effects. Bone. 2011;48:677-92. 42. Papapoulos S, Chapurlat R, Libanati C, Brandi ML, Brown JP, Czerwiński E, et al. Five years of denosumab exposure in women with postmenopausal osteoporosis: results from the first two years of the FREEDOM extension. J Bone Miner Res. 2012;27:694-701.

43. Mander KA, Finnie JW. Tumor angiogenesis, anti-angiogenic therapy and chemotherapeutic resistance. Aust Vet J. 2018;96:371-8. 44. Pimolbutr K, Porter S, Fedele S. Osteonecrosis of the Jaw Associated with Antiangiogenics in Antiresorptive-Naïve Patient: A Comprehensive Review of the Literature. Biomed Res Int 2018;2018:8071579

45. Chang J, Hakam AE, McCauley LK. Current Understanding of the Pathophysiology of Osteonecrosis of the Jaw. Curr Osteoporos Rep. 2018;16:584-95.

46. Aldridge SE, Lennard TW, Williams JR, Birch MA. Vascular endothelial growth factor receptors in osteoclast differentiation and function. Biochem Biophys Res Commun. 2005;335:793-8.

47. Pazianas M. Osteonecrosis of the jaw and the role of macrophages. J Natl Cancer Inst. 2011;103:232-40.

48. Zarringhalam P, Brizman E, Shakib K. Medication-related osteonecrosis of the jaw associated with aflibercept. Br J Oral Maxillofac Surg. 2017;55:314-5.

49. Won AM, Boddu P, Otun AO, Aponte-Wesson R, Chambers M. Chronic myelogenous leukemia presenting with osteonecrosis of the jaw as a rare but debilitating toxicity of dasatinib: a case report and literature review. Oral Surg Oral Med Oral Pathol Oral Radiol. 2018;126:e208-11.

50. Abel Mahedi Mohamed H, Nielsen CEN, Schiodt M. Medication related osteonecrosis of the jaws associated with targeted therapy as monotherapy and in combination with antiresorptives. A report of 7 cases from the Copenhagen Cohort. Oral Surg Oral Med Oral Pathol Oral Radiol. 2018;125:157-63.

51. Viviano M, Rossi M, Cocca S. A rare case of osteonecrosis of the jaw related to imatinib. J Korean Assoc Oral Maxillofac Surg. 2017:43:120-4

52. Patel V, Sproat C, Kwok J, Tanna N. Axitinib-related osteonecrosis of the jaw. Oral Surg Oral Med Oral Pathol Oral Radiol. 2017;124:e257-60

53. Garuti F, Camelli V, Spinardi L, Bucci L, Trevisani F. Osteonecrosis of the jaw during sorafenib therapy for hepatocellular carci- 
noma. Tumori. 2016;102(Suppl. 2).

54. Marino R, Orlandi F, Arecco F, Gandolfo S, Pentenero M. Osteonecrosis of the jaw in a patient receiving cabozantinib. Aust Dent J. 2015;60:528-31.

55. Magremanne M, Lahon M, De Ceulaer J, Reychler H. Unusual bevacizumab-related complication of an oral infection. J Oral Maxillofac Surg. 2013;71:53-5

56. Wolfe RM, Ang DC. Biologic Therapies for Autoimmune and Connective Tissue Diseases. Immunol Allergy Clin North Am. 2017;37:283-99.

57. Sfikakis PP. The first decade of biologic TNF antagonists in clinical practice: lessons learned, unresolved issues and future directions. Curr Dir Autoimmun. 2010;11:180-210.

58. Favia G, Tempesta A, Limongelli L, Crincoli V, Iannone F, Lapadula G, Maiorano E. A Case of Osteonecrosis of the Jaw in a Patient with Crohn's Disease Treated with Infliximab. Am J Case Rep. 2017;18:1351-6.

59. Cassoni A, Romeo U, Terenzi V, Della Monaca M, Rajabtork Zadeh O, Raponi I, et al. Adalimumab: Another Medication Related to Osteonecrosis of the Jaws?. Case Rep Dent. 2016;2016:2856926.

60. Preidl RH, Ebker T, Raithel M, Wehrhan F, Neukam FW, Stockmann P. Osteonecrosis of the jaw in a Crohn's disease patient following a course of Bisphosphonate and Adalimumab therapy: a case report. BMC Gastroenterol. 2014;14:6.

61. Keribin P, Guerrot D, Jardin F, Moizan H. Osteonecrosis of the Jaw in a Patient Presenting With Post-Transplantation Lymphoproliferative Disorder Treated With Rituximab: A Case Report. J Oral Maxillofac Surg. 2017;75:2599-605.

62. Allegra A, Oteri G, Alonci A, Bacci F, Penna G, Minardi V, et al. Association of osteonecrosis of the jaws and POEMS syndrome in a patient assuming rituximab. J Craniomaxillofac Surg. 2014;42:279-82. 63. Davignon JL, Rauwel B, Degboé Y, Constantin A, Boyer JF, Kruglov A, Cantagrel A. Modulation of T-cell responses by anti-tumor necrosis factor treatments in rheumatoid arthritis: a review. Arthritis Res Ther. 2018;20:229.

64. Weinstein RS. Glucocorticoid-induced osteonecrosis. Endocrine. 2012;41:183-90.

65. Powell C, Chang C, Gershwin ME. Current concepts on the pathogenesis and natural history of steroid-induced osteonecrosis. Clin Rev Allergy Immunol. 2011;41:102-13.

66. Berti-Couto SA, Vasconcelos AC, Iglesias JE, Figueiredo MA, Salum FG, Cherubini K. Diabetes mellitus and corticotherapy as risk factors for alendronate-related osteonecrosis of the jaws: a study in Wistar rats. Head Neck. 2014;36:84-93.

67. Di Fede O, Bedogni A, Giancola F, Saia G, Bettini G, Toia F, et al. BRONJ in patients with rheumatoid arthritis: a multicenter case series. Oral Dis. 2016;22:543-8.

68. Aletaha D, Smolen JS. Diagnosis and Management of Rheumatoid Arthritis: A Review. JAMA. 2018;320:1360-72.

69. van Dalen EC, van As JW, de Camargo B. Methotrexate for highgrade osteosarcoma in children and young adults. Cochrane Database Syst Rev. 2011;5:CD006325.

70. Furukawa S, Oobu K, Moriyama M, Kawano S, Sako S, Hayashida JN, et al. Oral Methotrexate-related Lymphoproliferative Disease Presenting with Severe Osteonecrosis of the Jaw: A Case Report and Literature Review. Intern Med. 2018;57:575-81.

71. Furudate K, Satake A, Narita N, Kobayashi W. Methotrexate-Related Lymphoproliferative Disorder in Patients With Osteonecrosis of the Jaw: A 3-Case Report and Literature Review. J Oral Maxillofac Surg. 2018;76:97-111.

72. Henien M, Carey B, Hullah E, Sproat C, Patel V. Methotrexateassociated osteonecrosis of the jaw: A report of two cases. Oral Surg Oral Med Oral Pathol Oral Radiol. 2017;124:e283-7.

73. Wang W, Zhou H, Liu L. Side effects of methotrexate therapy for rheumatoid arthritis: A systematic review. Eur J Med Chem. 2018;158:502-16.

74. Chan ES, Cronstein BN. Mechanisms of action of methotrexate. Bull Hosp Jt Dis. 2013;71:S5-8.

75. Kezic A, Popovic L, Lalic K. mTOR Inhibitor Therapy and Meta- bolic Consequences: Where Do We Stand? Oxid Med Cell Longev. 2018;2018:2640342.

76. Konings IR, Verweij J, Wiemer EA, Sleijfer S. The applicability of mTOR inhibition in solid tumors. Curr Cancer Drug Targets. 2009;9:439-50.

77. Giancola F, Campisi G, Lo Russo L, Muzio LL, Di Fede O. Osteonecrosis of the jaw related to everolimus and bisphosphonate: a unique case report?. Ann Stomatol (Roma). 2013;4:20-1.

78. Omarini C, Filieri ME, Depenni R, Grizzi G, Cascinu S, Piacentini F. Osteonecrosis of the Jaw in a Breast Cancer Patient Treated with Everolimus and a Single Dose of Zoledronic Acid. Breast J. 2017;23:610-1.

79. Nifosì AF, Nifosì L, Nifosì G. Osteonecrosis of the Jaw in a Patient Treated with Denosumab and Temsirolimus. SAJ Case Rep. 2017;4:401.

80. Kim DW, Jung YS, Park HS, Jung HD. Osteonecrosis of the jaw related to everolimus: a case report. Br J Oral Maxillofac Surg. 2013;51:e302-4.

81. Faes S, Santoro T, Demartines N, Dormond O. Evolving Significance and Future Relevance of Anti-Angiogenic Activity of mTOR Inhibitors in Cancer Therapy. Cancers (Basel). 2017;9:E152.

82. Yamamoto D, Tsubota Y, Utsunomiya T, Sueoka N, Ueda A, Endo K, et al. Osteonecrosis of the jaw associated with everolimus: A case report. Mol Clin Oncol. 2017;6:255-7.

83. Owosho AA, Scordo M, Yom SK, Randazzo J, Chapman PB, Huryn JM, et al. Osteonecrosis of the jaw a new complication related to Ipilimumab. Oral Oncol. 2015;51:e100-1.

84. Nicolatou-Galitis O, Galiti D, Moschogianni M, Sachanas S, Edwards BJ, Migliorati CA, et al. Osteonecrosis of the jaw in a patient with acute myeloid leukemia, who received azacitidine. J Cancer Metasta Treat. 2016;2:220-3.

\section{Funding}

None declared.

\section{Conflict of interest}

Conclusions of the working group on "New drugs related to the development of osteonecrosis of the jaw". Spanish Society of Craniomandibular Dysfunction and Orofacial Pain and Spanish Society of Oral Medicine SEDCYDO-SEMO joint International Meeting: 30th SEDCYDO annual meeting \& 15th SEMO Congress. Bilbao (Spain); June, 2019. 